\title{
Sahanaya: A Virtual Friend
}

\author{
Dissanayake D. M. A. S \\ University of SLIIT \\ Sri Lanka
}

\author{
Ganegoda V. D. B \\ University of SLIIT \\ Sri Lanka
}

\author{
Dissanayake D. M. R. S \\ University of SLIIT \\ Sri Lanka
}

Muhandiramge R. U. D
University of SLIIT
Sri Lanka

\author{
Ellepola N. \\ Lecture at University of SLIIT \\ Sri Lanka
}

\begin{abstract}
"Sahanaya", is an Artificial Intelligence (AI) based chatbot application and artificial Intelligence is going to be one of the most important technologies in the coming days. Since today's rapidly growing android mobile application market, the project group decided to develop the "Sahanaya" which is an AI based intelligent chatbot application as a mobile based android application. Since the population are living in a modern world most of the people do not have a very close family background, close friends, relations or anyone by their side to help in the situations when cannot discuss or share about emotions, problems and complications. Even many people aware of that they have psychiatric issues; they are reluctant to channel a psychological consultant due to various reasons like channeling cost, busy life, ashamed of themselves and etc. This is a tragedy most of the people are facing. To fulfil the need of an AI based psychological chatbot application which can provide the accurate information, measurements and detections about user stress level; synthesized the advancement of the "Sahanaya" application. The main function of "Sahanaya" is providing the user stress level through the calculations and measurements which is specific to each user by using the user chat history and stress level detection for each user based on their psychological issues. By using the "Sahanaya" application users are capable of sharing their day to day problems as well as emotional feelings they have. The application users have the ability to text each and every problem with this app. In the meantime, the app replies to the user according to the psychiatric issues the user has and smart answers are given by the "Sahanaya". This "Sahanaya" application has multiple knowledge sources and choose the best answer to reply users. "Sahanaya" keeps track of each and every conversations between the users. After detecting the user stress level the application ultimately recommend to have a consultation with a psychological consultants to the users. Climactically the "Sahanaya" helps to find the right balance in the life by taking care of people psychologically and optimize the intellectual healthiness.
\end{abstract}

\section{Keywords}

Artificial Intelligence (AI), Chatbot, AI based mobile apps, AI based health applications, Stress detection, stress calculation.
Table 1. Definition, Acronym, Abbreviations

\begin{tabular}{|l|l|}
\hline Term & Definition, Acronym, Abbreviations \\
\hline AI & $\begin{array}{l}\text { Artificial intelligence } \\
\text { An intelligence exhibited by machines in } \\
\text { computer science. }\end{array}$ \\
\hline API & $\begin{array}{l}\text { Application Program Interface. } \\
\text { It is a set of routines, protocols and tools for } \\
\text { building software applications. }\end{array}$ \\
\hline Chatbot & $\begin{array}{l}\text { A computer program which conducts a } \\
\text { conversation via auditory or textual methods. }\end{array}$ \\
\hline Physiology & $\begin{array}{l}\text { The way in which a living organism or } \\
\text { bodily part functions. }\end{array}$ \\
\hline Database & $\begin{array}{l}\text { Collection of all the information monitored } \\
\text { by this system. }\end{array}$ \\
\hline Stakeholder & $\begin{array}{l}\text { Any person with an interest in the project } \\
\text { who is not a developer. }\end{array}$ \\
\hline SQL & $\begin{array}{l}\text { User Interface. } \\
\text { Set of commands or menus through which a } \\
\text { user communicates with a program. } \\
\text { Special-purpose programming language } \\
\text { relational database management system }\end{array}$ \\
\hline
\end{tabular}

\section{INTRODUCTION}

Mental health is important at every stage of life, from childhood and adolescence through adulthood [1]. At the present there are many AI based applications such as Tess, Babylon, Sense.ly: Virtual Visits Real Care, AiCure does the job of take care about the health of the patients, psychoeducation and health-related reminders to the users and those applications are not helping out people to raise their mental health includes emotional, psychological and social wellbeing [2]. The "Sahanaya" application helps people to optimize their mental health includes emotional, psychological and social well-being. "Sahanaya" helps to handle stress of peoples' lives and help them to make their life goals, choices easier. The "Sahanaya" application prospected 
how to leave the stress, emotional feelings and problems that do not want to express others, how to detect the stress level of a person and how to generate, select the matching questions to the answers given by the users.

Depression or the stress affects people of all ages, from all walks of life, in all countries. It causes psychological severe upset or pain and impacts on people's ability to carry out. When human body goes into a state of stress, it may feel agitated and aggressive towards others; this can be due to human bodies' natural reaction being "fight". This can be a helpful reaction toward off predators, but in unnecessary situations, it can negatively affect relationships and ruin the character personality.

Stress can lead the lives towards memory problems, poor judgment, inability to concentrate and starting many tasks but achieving little self-doubt. The stress gives the emotional attacks like depression, moodiness, irritability, fatalistic thinking, panic, anxiety, feeling overwhelmed, and frustration. More over ultimately stress lead human body towards to chest pain, rapid heartbeat, aches and pains, frequent colds, skin complaints, high blood pressure. The application "sahanaya", is an AI based intelligent chatbot application that can give smart answers according to the user questions. This application helps the situations when people cannot discuss or share about emotional feelings and problems with each other. By using this "Sahanaya" application, it can share day to day problems as well as emotional feelings. The main abilities of this app is, it is providing the user stress level through the calculations and measurements which is specific to each user by using the user chat history, stress level detection for each user based on their psychological issues, mental health according to the user stress level. The application users can text each problem with this application. In the meantime the app is replying to the user according to the problems the user has and is giving smart answers. The "Sahanaya" application is having multiple knowledge sources and choose the best answer to reply users. This app is keeping track of each and every conversation between the users and is providing stress level information to the user after looked in to the user chat history. This application helps people to optimize their mental health includes emotional, psychological and social wellbeing. The application helps to handle stress of peoples' lives and help people to make their life goals, choices easier.

The research targets the people already suffering from stress and people who are do not know about their stress level. The research team developed a mobile application for make it easier in use among them. The application, "Sahanaya" detects the stress level and identify the overall stress level throughout the chat conversion history. The users do not need to register for the application; it helps to take care of privacy issues since today's all the communication media is lack of privacy in to some level.

The "Sahanaya" application first start a normal conversation among the user and after a while "Sahanaya" asks questions that are psychologically based. When user answers those psychological questions "Sahanaya" track those answers given by the users and takes a word count of words that are related to the stress, depression, moodiness, irritability, fatalisticthinking, panic, anxiety, feeling overwhelmed, and frustration. When the user feels that want to know about the stress level; the user can view the stress level without any hesitations. The "Sahanaya" is full of privacy since it is not taking user details at the beginning. "Sahanaya" displays the stress level according to the correct calculations and measurements throughout the chat history. When if the user with more stress or the user is in a severe situation the "Sahanaya" recommends to user to meet a psychiatrist as soon as possible as an ultimate solution.

The architectural design of the "Sahanaya" application is shown in the Figure 1.

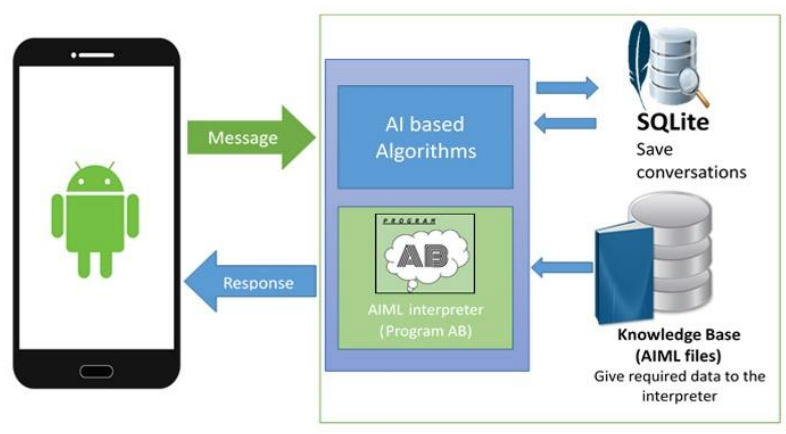

Fig 1: Architecture diagram

Though there are many popular AI based chatbots there are none that has the ability of detecting the user stress level [3]. "Sahanaya" application achieved the objects of developing an AI based mobile application especially for helping people in the situations when cannot discuss or share about emotional feelings and problems with each other, developing an algorithm to map the answers according to the user questions, detecting the stress level of the users based on their conversations, providing accurate information about stress level according to the user chat history and that optimize the mental health level of the users step by step providing smart answers according to the user problems. In order to build the "Sahanaya" application it has been used some advanced technologies like Artificial intelligence and analytics. Therefore the system has smart algorithms to work with the other components, like AI based algorithms to get the maximum result of this system.

\section{BACKGROUND}

Artificial intelligence is a branch of computer science dealing with the simulation of intelligent behavior in computers [4]. In this research, the "Sahanaya" application is capable of imitate intelligent human behavior to communicate/deal with the end user. The "Sahanaya" is an AI based chatbot application that mainly focused for detecting the stress level of the users according to the conversations they are having with the application. Detecting the stress level is achieved by keeping track of each and every conversations between the users. This application gives smart answers to the user according to the problems they are discussing with the application. To the mean time the "Sahanaya" application is focusing only on family problems. All responses and answers are based on the developed knowledgebase which built in the application. The "Sahanaya" application came across to the solutions through the detected stress level of users.

A.L.I.C.E was only a natural language processing chatbot; a program that engages in a conversation with a human by applying some heuristically pattern matching rules to the human's input. This application was created by Richard Wallace in in 1995 [5]. In 2016 Tay an AI program that ran a mostly Twitter-based bot was created by Microsoft. Due to its obscene and inflammatory tweets Tay was shut down after one day. [6]. Babaylon the world's first artificial intelligence triage platform and gives Online Doctor Consultations \& Advices has been brought into existence in 2016. This 
application enables users to have virtual consultations with doctors and health care professionals via text and video messaging through its mobile application. The service also allows users to receive drug prescriptions, referrals to health specialists, and book health exams with nearby facilities [7].In 2016 Sense.ly: virtual visits real care application has been founded. That provides proven, personalized patient monitoring and follow-up care and it was the latest advances in artificial intelligence to build customized virtual assistant applications for the healthcare industry [8].

Most of the apps were not based on mental health except the application Tess, developed in 2016. Tess is an AI based psychological chatbot application that administers psychoeducation and health-related reminders to the users [9]. It is needed to mention that the some use cases the Tess has; natural evaluation of health course, questionnaire automation, improving therapy adherence, coping with mental issues tied to medication, making psychological aid more approachable made the Tess more related to the psychological chatbot. It is important to address that the Tess cannot detect the user stress level according to the conversion of users

The research team have been found out the lack of functions of all the existing chatbots and the research team has been identified the need of an AI based psychological chatbot which can provide smart answers according to the user problems, that can detects the user stress level through the user conversations.

"Sahanaya" was developed to help the people already suffering from stress and people who do not know about their stress level. Through the implemented system the user can finally get the stress level of their own. "Sahanaya" also gives solutions for the minor complications users are facing. During the development period the team had to face logical challenges. Following are some of the major challenges faced by the research group.

- Build or adjusting algorithms to achieve accurate results

- Retrieving answers from logical questions.

To avoid the listed problems, the team had to seek for support from other individuals such as Software Developers in the industry and to refer tutorials, researches, books etc. related to algorithm development. Although it was originally planned to suggest the psychological consultant to the users but due to ethical reasons and rules practiced by the medical experts the research group was informed to not to suggest any specific psychiatrists. Therefore the application only tells the user to just go and meet a psychiatrist as the ultimate solution based on the user stress level results.

The research group members decided to get data for the research by interviewing medical experts who is under the category psychiatry. The group discussed about different stress levels of people, how to identify the stages of stress levels, how to measure the stress level of people in a psychological manner, how to give answers to the people in a psychology.

\section{METHODOLOGY}

Prototype methodology adopted for the development of the "Sahanaya" application because this method has ability to quickly refine real system requirements. And also significantly reduces the risk of failure, as potential risks can be identified in early stage and moderation steps can be taken quickly. Software errors can be detected earlier in this methodology.
When moving in to requirement gathering and analysis the major tasks were gathering the requirements and analyzing the functional needs such as deciding the architecture and the user interfaces, analyzing non-functional needs such as usability and scalability. Gathering the requirements done by interviewing two medical students.

In the design phase project team quick/preliminary designed user interfaces, knowledge base and Algorithms. Those were not detail designs, and include the important aspects of the system but which gave a clear idea of the system to the project stakeholders.

In Implementation phase project team created templates, chatbot models, code some important aspects of the system. Combining these aspects and quick designs that the project team created in earlier stage, modified to a prototype. It represents rough design of the required system. After created a prototype it presented to the project stakeholders for consideration as part of the development process. Once the project stakeholders evaluated the prototype, it is refined according to the requirement. When the all project stakeholders satisfied with the developed prototype, the final system developed based on the final prototype.

The last phase the testing phase, project team found out whether the code and programming are working according to the system requirements. There are different types of testing will be performed including Unit, integration and system testing. User acceptance testing was the last part of this testing phase and performed by the end users

\subsection{Flow Chart for the Stress Level Calculating Algorithm}

The figure 2 illustrate the flow of "Sahanaya" application. It begins with a message saying "Hi!" to the user, then user can start conversation with the application. After getting the user's reply, first it send the message to algorithm called "WordCount". This algorithm separate all words of the message and count words that depressed, stressed people mostly use (example: alone, busy), after that it check the count of the words are beyond the limit or not. After that system check the question count is beyond the limit or not. Question count keep record of the latest question's number that the system asked. If it is not beyond the word count, the user's message send to the knowledgebase and get suitable reply for it, and send that reply to the user. But if it is beyond the limit, system check the question count is less than the limit. If the question count is beyond the limit, again it send to knowledgebase, get suitable reply and send it to user. But it is less than the limit then the system will check the message is a question or not. If it is a question, again send a reply from the knowledgebase. And if it is not a question then system start or continue asking questions from the user. Every answer is going through the "AskQuestionsAndGetAnswers" and "CalculatePoints"algorithms.

"AskQuestionsAndGetAnswers" algorithm get and save answers, and send another question to the user. Same time "CalculatePoints" algorithm give points for the user's answer and give points to the word count. After all calculations done, system send final result about user's stress level to the user and after the final result all replies for the user messages will get from the knowledgebase. 


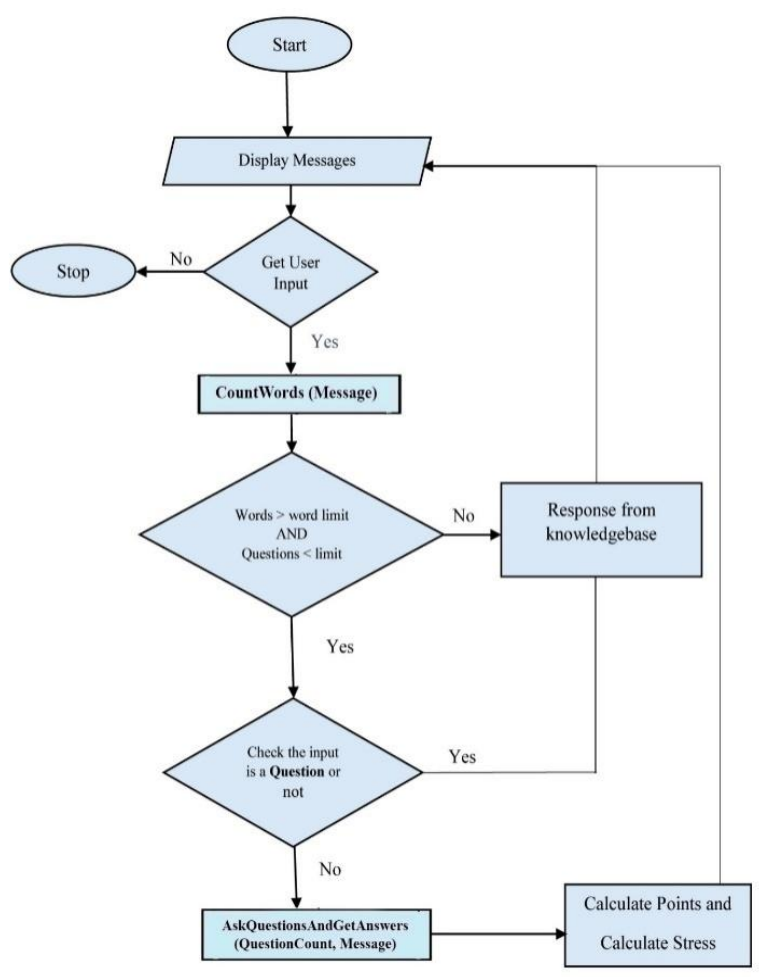

Fig 2: Flow chart of the stress level calculating algorithm

\subsection{The Development of "Sahanaya"}

String variable named "message". Then next code line will clear the user's text typing area. After that the message send to the message list view and focus that message. Next display the system status as "typing..." in title bar.

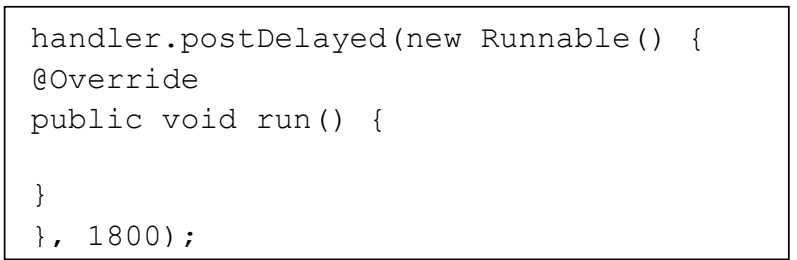

In "handler.postDelayed" method, this will execute all the code segments in the method body after 1800 milliseconds. That means after 1.8 seconds. Purpose of using this method is to make realistic environment for the user. Because all the response selection codes are written inside this method.

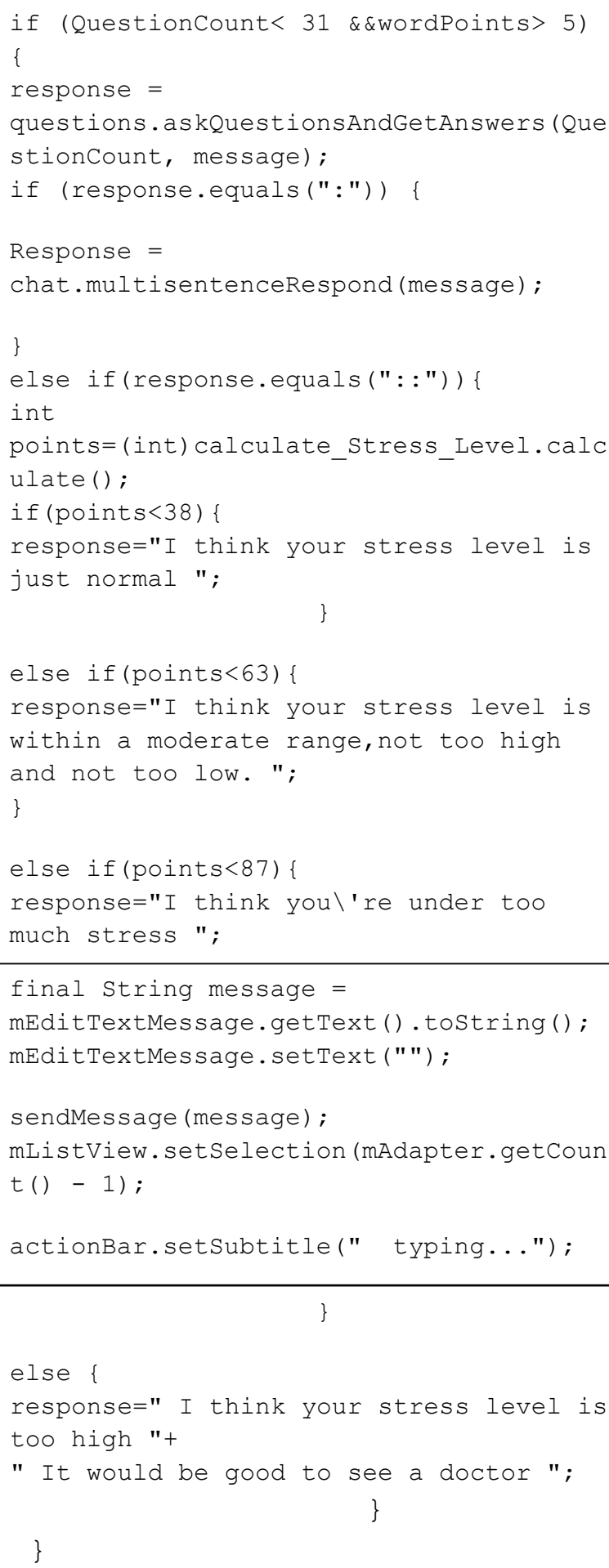


This code segment will decide whether the response selected from the knowledgebase or from the system (A.I algorithm). First it check the question count is less than 31 , it because system has 15 questions and 15 answers getting methods. After that it will check the word points are greater than 5. If both conditions are true, response selected from the system (calling ask Questions And Get Answers method). If the conditions are false or system send ":" symbol as output, response selected from the knowledgebase (“:” symbol indicate user ask a question, after the system ask a question for calculate user's stress level). If "::" symbol get for the output means user's stress level calculation is completed. After that system will send user's current stress level status for the user.

\subsection{The Testing}

Without a well-thought testing effort, the project will undoubtedly fail overall and will impact the entire operational performance of the solution. The testing were carried out by giving the "Sahanaya" application to several users and also with some sample data testing was done by the researched team.

Table 2: Level of accuracy when using the application

\begin{tabular}{|c|c|c|c|c|}
\hline Users & $\begin{array}{c}\text { Specific } \\
\text { words of the } \\
\text { conversation }\end{array}$ & $\begin{array}{l}\text { Words } \\
\text { points }\end{array}$ & $\begin{array}{l}\text { Stress } \\
\text { level } \\
\text { value }\end{array}$ & Final result \\
\hline $\begin{array}{c}\text { User } \\
1\end{array}$ & $\begin{array}{l}\text { "Feeling } \\
\text { headache", } \\
\text { "Feeling so } \\
\text { tired", } \\
\text { "Money } \\
\text { problems" }\end{array}$ & 17 & $61 \%$ & $\begin{array}{l}\text { Category: } \\
\text { Optimum } \\
\text { Stress } \\
\text { Stress level is } \\
\text { within a } \\
\text { moderate } \\
\text { range, not too } \\
\text { high and not } \\
\text { too low. }\end{array}$ \\
\hline $\begin{array}{c}\text { User } \\
2\end{array}$ & $\begin{array}{l}\text { "Suicide", } \\
\text { "Kill } \\
\text { myself", } \\
\text { "Lonely", } \\
\text { "depressed" }\end{array}$ & 24 & $89 \%$ & $\begin{array}{l}\text { Category: } \\
\text { Burn out } \\
\text { stress level is } \\
\text { too high } \\
\text { system } \\
\text { recommend } \\
\text { user, to meet } \\
\text { a doctor }\end{array}$ \\
\hline $\begin{array}{c}\text { User } \\
3\end{array}$ & $\begin{array}{l}\text { "Full of } \\
\text { work", } \\
\text { "Busy life", } \\
\text { "Working } \\
\text { hard", "Can't } \\
\text { sleep } \\
\text { properly" }\end{array}$ & 19 & $71 \%$ & $\begin{array}{l}\text { Category: } \\
\text { Overload } \\
\text { User under } \\
\text { too much } \\
\text { stress }\end{array}$ \\
\hline $\begin{array}{c}\text { User } \\
4\end{array}$ & $\begin{array}{l}\text { "depressed", } \\
\text { "Full of } \\
\text { stress", } \\
\text { "Exams", } \\
\text { "Anxious"”, }\end{array}$ & 15 & $58 \%$ & $\begin{array}{l}\text { Category: } \\
\text { Optimum } \\
\text { Stress } \\
\text { Stress level is } \\
\text { within a } \\
\text { moderate } \\
\text { range, not } \\
\text { too high and }\end{array}$ \\
\hline
\end{tabular}

\begin{tabular}{|c|c|c|c|c|}
\hline & & & & not too low. \\
\hline $\begin{array}{c}\text { User } \\
5\end{array}$ & $\begin{array}{l}\text { "relax", } \\
\text { "complain"," } \\
\text { selfish", } \\
\text { "hate } \\
\text { ", "happy", } \\
\text { "good" }\end{array}$ & 11 & $36 \%$ & $\begin{array}{l}\text { Category: } \\
\text { Normal } \\
\text { User's stress } \\
\text { level is } \\
\text { normal }\end{array}$ \\
\hline $\begin{array}{c}\text { User } \\
6\end{array}$ & $\begin{array}{l}\text { "headache", } \\
\text { "blame", } \\
\text { "relationship } \\
\text { problems", } \\
\text { "worried", } \\
\text { "not busy" }\end{array}$ & 20 & $63 \%$ & $\begin{array}{l}\text { Category: } \\
\text { Optimum } \\
\text { Stress } \\
\text { Stress level is } \\
\text { within a } \\
\text { moderate } \\
\text { range, not } \\
\text { too high and } \\
\text { not too low. }\end{array}$ \\
\hline $\begin{array}{c}\text { User } \\
7\end{array}$ & $\begin{array}{l}\text { "enjoy", } \\
\text { "Busy", } \\
\text { "sleepy", } \\
\text { "friendly", } \\
\text { "over think", }\end{array}$ & 8 & $34 \%$ & $\begin{array}{l}\text { Category: } \\
\text { Normal } \\
\text { User's stress } \\
\text { level is } \\
\text { normal }\end{array}$ \\
\hline
\end{tabular}
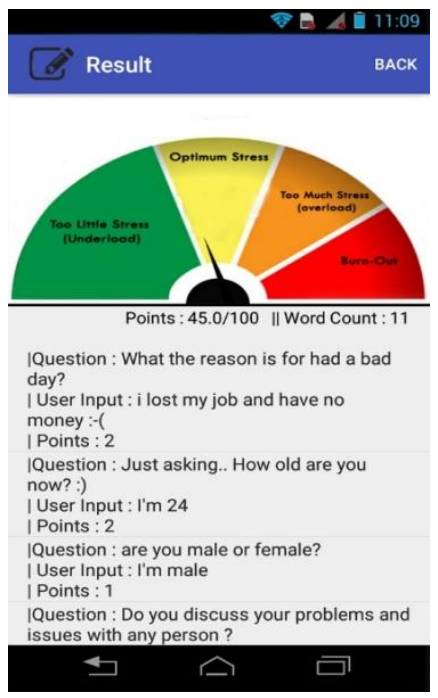

Fig 3: Stress meter

Figure 3 describes that User can view their stress level. The stress meter display the stress level which belongs to the user according to calculations and measurements with their chat history.

\section{CONCLUTIONS}

The main aim of this research is to build a chatbot application especially for helping people in the situations when cannot 
discuss or share about emotional feelings and family problems with each other. The "Sahanaya" application provides accurate information and calculations about according to the user stress level and optimizes the metal health.

The application "Sahanaya" was developed with the main objective of detect the stress category of the users and finding the stress level. This application contributes widely in identifying the type of the problems in finance, relationship conflicts and family. In the real world circumstances, psychiatrists' charges a lot for examine a patient. By using this "Sahanaya" application; it was confirmed by the resting it can identify and detect the stress of a person and give solutions for their matters. That helps largely for the users to decide the psychological treatment needed or not for them easily. This application can be downloaded and installed easily and with the user friendly environment the user will willingly use this application and hence it will give a better outcome.

\section{ACKNOWLEDGEMENTS}

It would be a pleasure to acknowledge and extend our genuine appreciation to everyone who has made the completion of this project possible. Especial thanks goes to Ms.Nideshika Ellepola for her supervision, coordination and reassurance provided throughout the project as the project supervisor and Mrs.Gayana Fernando who conducted through this research.

\section{REFERENCES}

[1] "Cite a Website - Cite This For Me", Ijoc.org, 2017. [Online]. Available: http://ijoc.org/index.php/ijoc/article/viewFile/6277/1804. [Accessed: 29- Mar- 2017].

[2] 2017.

[Online].

Available: https://www.chatbots.org/chatbot/a.l.i.c.e/. [Accessed: 29- Mar- 2017].

[3] 2017 [Online]. Available: http://www.scielo.org.mx/pdf/cys/v19n4/1405-5546-cys19-04-00625.pdf. [Accessed: 29- Mar- 2017].

[4] "Tay AI", Know YourMeme,2017[Online].Available: http://knowyourmeme.com/memes/sites/tay-ai. [Accessed: 29- Mar- 2017].

[5] M. Yao and M. Yao, "5 Metrics Every Chatbot Should Track - TOPBOTS", TOPBOTS, 2017. [Online].

[6] Available: http://www.topbots.com/5-bot-metrics-everychatbot-should-track/. [Accessed: 29- Mar- 2017].

[7] 2017.[Online].Available:http://delivery.acm.org/10.1145/ $1560000 / 1556341 / \mathrm{p} 89$ shawar.pdf?ip=112.134.96.7\&id= $1556341 \&$ acc $=$ OPEN\&key $=4 \mathrm{D} 4702 \mathrm{~B} 0 \mathrm{C} 3 \mathrm{E} 38 \mathrm{~B} 35 \% 2 \mathrm{E} 4$ D4702B0C3E38B35\%2E4D4702B0C3E38B35\%2E6D2 $18144511 \mathrm{~F} 3437 \& \mathrm{CFID}=744606346 \& \mathrm{CFTOKEN}=5877$ $5665 \& \quad \mathrm{acm}=1490791070 \quad 273 \mathrm{ea} 883 \mathrm{~d} 2236 \mathrm{a} 953523 \mathrm{a}$ ca69e594023. [Accessed: 29- Mar- 2017].

[8] 2017.[Online].Available:https://pdfs.semanticscholar.org 17092/6d4b8909db07b90909a4a394c16bb64a3ecd.pdf. [Accessed: 29- Mar- 2017].

[9] b. App, "Online Doctor Consultations \& Advice", babylon, $2017 . \quad$ [Online]. Available: https://www.babylonhealth.com/. [Accessed: 29- Mar2017].

[10] "9 Startups Building AI Powered Chatbot Apps", Business of Apps, 2017. [Online]. Available: http://www.businessofapps.com/9-startups-building-aipowered-chatbot-apps/. [Accessed: 29- Mar- 2017].

[11] "Sense.ly | Virtual visits, real care.", Sense.ly, 2017. [Online]. Available: http://sense.ly/. [Accessed: 29- Mar2017]

[12] "Artificial Intelligence Will Redesign Healthcare - The Medical Futurist", The Medical Futurist, 2017. [Online] Available: $\quad \mathrm{http} / / /$ medicalfuturist.com/artificialintelligence-will-redesign-healthcare/. [Accessed: 29Mar- 2017]

[13] "AiCure: Advanced medication adherence solutions", AiCure, 2017. [Online]. Available: https://aicure.com/. [Accessed: 29- Mar- 2017].

[14] X. Inc., "X2AI", X2AI, 2017. [Online]. Available: https://x2.ai/. [Accessed: 29- Mar- 2017].

[15] B. Lerner, S. Parkin, P. Byrnes, C. Kormann, R. Lizza, A. Borowitz, P. Byrnes, J. Groopman, N. Romeo, R. Lizza, A. Borowitz, P. Byrnes, J. Groopman, C. Kormann, A. Lydgate, R. Nuila, R. Lizza and A Borowitz, "The Chatbot Will See You Now", The New Yorker, 2017. [Online]. Available: http://www.newyorker.com/tech/elements/the-chatbotwill-see-you-now. [Accessed: 29- Mar- 2017].

[16] $2017 . \quad$ [Online]. Available: http://uksim.info/isms2016/CD/data/0665a072.pdf. [Accessed: 29- Mar- 2017].

[17] 2017 [Online].Available: https://scholarspace.manoa.hawaii.edu/bitstream/10125/4 1285/1/paper0136.pdf. [Accessed: 29- Mar- 2017].

[18] 2017. [Online].

Available: http://www.temjournal.com/content/52/TemJournalMay2 016_236_240.pdf. [Accessed: 29- Mar- 2017].

[19] "Cite a Website - Cite This For Me", Aclweb.org, 2017. [Online]. Available: http://aclweb.org/anthology/P161049. [Accessed: 29- Mar- 2017].

[20] $2017 . \quad$ [Online]. Available: https://www.jstage.jst.go.jp/article/ijae/15/2/15_IJAE-D15-00029/_pdf. [Accessed: 29- Mar- 2017].

[21] "Health Information Science", Google Books, 2017. [Online]. Available: https://books.google.lk/books?hl=en\&lr=\&id=O7klCQA AQBAJ\&oi=fnd\&pg=PA133\&dq=detecting+stress+leve 1+using $+\mathrm{a}+$ chatbot\&ots $=\mathrm{F}-$ 8 8Sr26N\&sig=eGtzDSjSOXn9bW5hTNHKnbCBNMY \&redir_esc $=\mathrm{y} \# \mathrm{v}=$ onepage $\& \mathrm{q}=$ detecting $\% 20$ stress $\% 20 \mathrm{lev}$ el\%20using\%20a\%20chatbot\&f=false. [Accessed: 30Mar- 2017]

[22] 2017.[Online].Available: http://ijesc.org/upload/2b6459ece3f4f7c5462ab995e8af4 46e.Desktop\%20Partner.pdf. [Accessed: 30- Mar- 2017]

[23] "Stress Check by Azumio | Wellocracy", Wellocracy, $2017 . \quad$ [Online]. Available: http://www.wellocracy.com/heart-health-trackers/hearthealth-tracker-chart/stress-check-azumio/. [Accessed: 30 Mar- 2017].

[24] "C.L.A.U.D.I.O. Personality Test Bot (A.L.I.C.E. AI Foundation)", Alicebot.org, 2017. [Online]. Available: http://www.alicebot.org/bios/richardwallace.html. [Accessed: 30- Mar- 2017]. 
[25] "Cite a Website - Cite This For Me", Itsum.files.wordpress.com, 2017. [Online]. Available: https://itsum.files.wordpress.com/2010/09/prototype.jpg. [Accessed: 01- Apr- 2017].

[26] 2017. [Online]. Available: https://www.quora.com/Whatare-some-smart-phone-apps-that-works-on-AI-basedalgorithms. [Accessed: 17- Mar- 2017].

[27] "AI Powered Mobile App Development", Artificial Brillance, Inc., 2017. [Online]. Available: http://artificialbrilliance.com/services/mobile-appdevelopment/. [Accessed: 17- Mar- 2017].

[28] 2017.[Online].Available:https://www.researchgate.net/pu blication/277138656_ANDROID_APPLICATIONS_WI
TH_ARTIFICIAL_INTELLIGENCE_IN_MOBILE_PH ONES. [Accessed: 17- Mar- 2017].

[29] L. Jayasinghe, L. Jayasinghe, L. Jayasinghe and L. Jayasinghe, "Best Artificial Intelligence Software for Android", TechPlusMe.com, 2017. [Online]. Available: http://www.techplusme.com/android/best-artificialintelligence-software-android. [Accessed: 17- Mar2017].

[30] R. Annunziato, N. Arrato, M. Rubes and R. Arnon, "The importance of mental health monitoring during transfer to adult care settings as examined among pediatric transplant recipients", 2017. [Accessed: 17- Mar- 2017]. 